\title{
Clinical features of visual migraine aura: a systematic review
}

\author{
Michele Viana ${ }^{1,2^{*}}$ (D), Erling Andreas Tronvik ${ }^{3,4}$, Thien Phu Do ${ }^{5}$, Chiara Zecca ${ }^{1,6}$ and Anders Hougaard ${ }^{5}$
}

\begin{abstract}
Background: Migraine aura (MA) is a common and disabling neurological condition, characterized by transient visual, and less frequently sensory and dysphasic aura disturbances.

MA is associated with an increased risk of cardiovascular disorders and is often clinically difficult to distinguish from other serious neurological disorders such as transient ischemic attacks and epilepsy. Optimal clinical classification of MA symptoms is important for more accurate diagnosis and improved understanding of the pathophysiology of MA through clinical studies.

Main body: A systematic review of previous prospective and retrospective systematic recordings of visual aura symptoms (VASs) was performed to provide an overview of the different types of visual phenomena occurring during MA and their respective frequencies in patients. We found 11 retrospective studies and three prospective studies systematically describing VASs. The number of different types of VASs reported by patients in the studies ranged from two to 23. The most common were flashes of bright light, "foggy" vision, zigzag lines, scotoma, small bright dots and 'like looking through heat waves or water'.

Conclusions: We created a comprehensive list of VAS types reported by migraine patients based on all currently available data from clinical studies, which can be used for testing and validation in future studies. We propose that, based on this work, an official list of VAS types should be developed, preferably within the context of the International Classification of Headache Disorders of the International Headache Society.
\end{abstract}

Keywords: Migraine aura, Migraine with aura, Visual symptoms, Visual disturbances, Scotoma, Clinical features, Scintillating scotoma, Zigzag lines, Blurred vision

\section{Introduction}

Migraine with typical aura is a highly prevalent disorder as it affects $8 \%$ of the general population [1]. Typical migraine aura (MA) symptoms are completely reversible visual, sensory, or language disturbances. Visual aura symptoms (VASs) are by far the most common and occur in $98-99 \%$ of MAs, whereas disturbances of sensation and language occur in $36 \%$ and $10 \%$ of auras, respectively [2]. In addition to being the most common aura symptoms, VASs are also the most multifaceted. In clinical studies of VAS, patients have reported a plethora of different, often complex, visual disturbances. Viana

\footnotetext{
* Correspondence: michele.viana@ymail.com

${ }^{1}$ Headache Center, Neurocenter of Southern Switzerland (NSI), Regional

Hospital Lugano, Via Tesserete 46, 6901 Lugano, Switzerland

${ }^{2}$ Headache Group, Department of Basic and Clinical Neurosciences, King's

College London, London, UK

Full list of author information is available at the end of the article
}

and colleagues previously observed that these visual phenomena could be effectively defined by subdividing the perceived visual scenarios into so-called elementary visual symptoms (EVS), such as zigzag lines, crescent shapes, and flickering lights [2].

Several studies have investigated the clinical features of VASs but so far there is no consensus regarding which different types of EVSs occur during MA and there is no agreement on the terminology that should be used to describe EVSs.

While MA is likely caused by cortical spreading depression, a transient wave of neuronal depolarization of the cortex [3-5], there is currently no pathophysiological explanation for the marked heterogeneity of visual symptoms. An accurate description of the clinical features, in combination with investigations such as neuroimaging, is necessary to provide a better understanding of the underlying mechanisms. 
Even more importantly, there are serious clinical issues related to MA that call for improved characterisation of the individual features. MA is associated with an increased risk of ischemic stroke [6, 7], atrial fibrillation [8], and patent foramen ovale [9]. It is also often clinically challenging to differentiate MA from other conditions, particularly transient ischemic attacks [10] and occipital epilepsy [11, 12]. Improved clinical characterisation of MA will likely improve the diagnostic accuracy and identification of patient subgroups at risk of comorbidity.

The aim of this article was to review all published studies providing systematic descriptions of VASs, with information on how frequently different EVSs are reported by MA patients. Based on these data, we aimed to create a comprehensive list of the different types of EVSs including their respective frequency of occurrence.

\section{Methods}

\section{Literature search}

The literature search was performed on June 1st 2018. We used the PubMed/MEDLINE database to identify published studies systematically investigating the clinical features of visual aura. The search string was (( "migraine with aura"[Title/Abstract]) OR "migraine aura"[Title/Abstract]) AND visual [Title/Abstract]). The bibliographies of all included studies were also searched as well as literature that was known to be relevant by the authors. Moreover, we considered the bibliography of the International Classification of Headache Disorders, Third Edition (ICHD-3) [13].

Inclusion criteria were a minimum of 10 migraine patients included where the features of VASs were described. We put this cut-off as generally small case series typically focus on unusual case presentations and are not able to provide an externally valid spectrum of manifestations. We felt that 10 was a reasonable number, although this was an (expert) agreement and not based on scientific evidence. In addition, only articles in English were considered. We excluded studies focusing exclusively on the description of visual disturbances relative to high-tier areas (i.e. prosopagnosia or dyschromatopsia). Furthermore, we did not consider articles exclusively relating to familial or sporadic hemiplegic migraine, basilar-type migraine, persistent auras or symptomatic (secondary) MA.

\section{Data extraction}

Two authors independently reviewed the abstracts found in the literature search (MV, $\mathrm{AH})$. If the title or abstract indicated relevant data, the entire manuscript was examined. Any disagreement between the two authors was resolved by consensus by involving a third person (ET). From included articles, we extracted for the following data categories: publication information (authors, years), population (number of patients), number of auras recorded, study methodology, description of visual aura disturbances, and their frequencies of occurrence on the total number of auras recorded.

\section{Procedure of composition of the list of EVSs}

We created a list of all EVSs with their respective frequency of occurrence (minimum and maximum values found in the studies). In case of discrepancy in the terminology for a given EVS, we reported all definitions. In the list, we included only EVS, and not any visual symptoms described by a combination of two or more EVSs (e.g. "scintillating scotoma").

\section{Results}

The search strategy identified 378 published studies (Fig. 1). Seventeen papers fulfilled our case definition [2, 14-29]. One study was excluded since "scintillating scotoma" (79.3\%) was the only VS reported [27]. It is likely that such description (not specified in the paper) was used to indicate any visual aura symptom, as no other type of visual disturbances were reported. We also excluded two manuscripts due to data not being systematically presented and since it was impossible to extract the frequency of occurrence of visual disturbances $[28,29]$. Key findings of the remaining 14 studies are summarized in Table 1.

In Table 2, we report a list of EVSs that have been described in at least one study. The minimum and maximum frequency of occurrence of each EVS is also provided here. "Scintillating scotoma" was not reported in the list as this it is a combination of two or more EVSs, i.e. "scotoma" and "zigzag or jagged lines" and/or "flickering light".

The total number of EVSs was 30. The frequency of each EVS varied from $1 \%$ to $91 \%$. Some EVSs were reported in one paper only (i.e. complex hallucinations, "slanted vision", "like a negative film" [16]) while others were reported in the majority of studies (flickering lights, bright light, zigzag lines, scotoma/hemianopsia).

\section{Discussion}

We systematically reviewed studies of VASs in order to create a list of all visual features reported during MA. We identified 14 studies, of which only three were prospective. The low number of prospective studies is a major limitation as the complex and polyhedral manifestations of MA are difficult to recall retrospectively.

\section{Main findings}

First, there is a high variability in the number of VASs used in each study, varying from two to 23 . The majority of the studies subdivide the VASs into four types (but not the same combination of four). Only in four studies, 


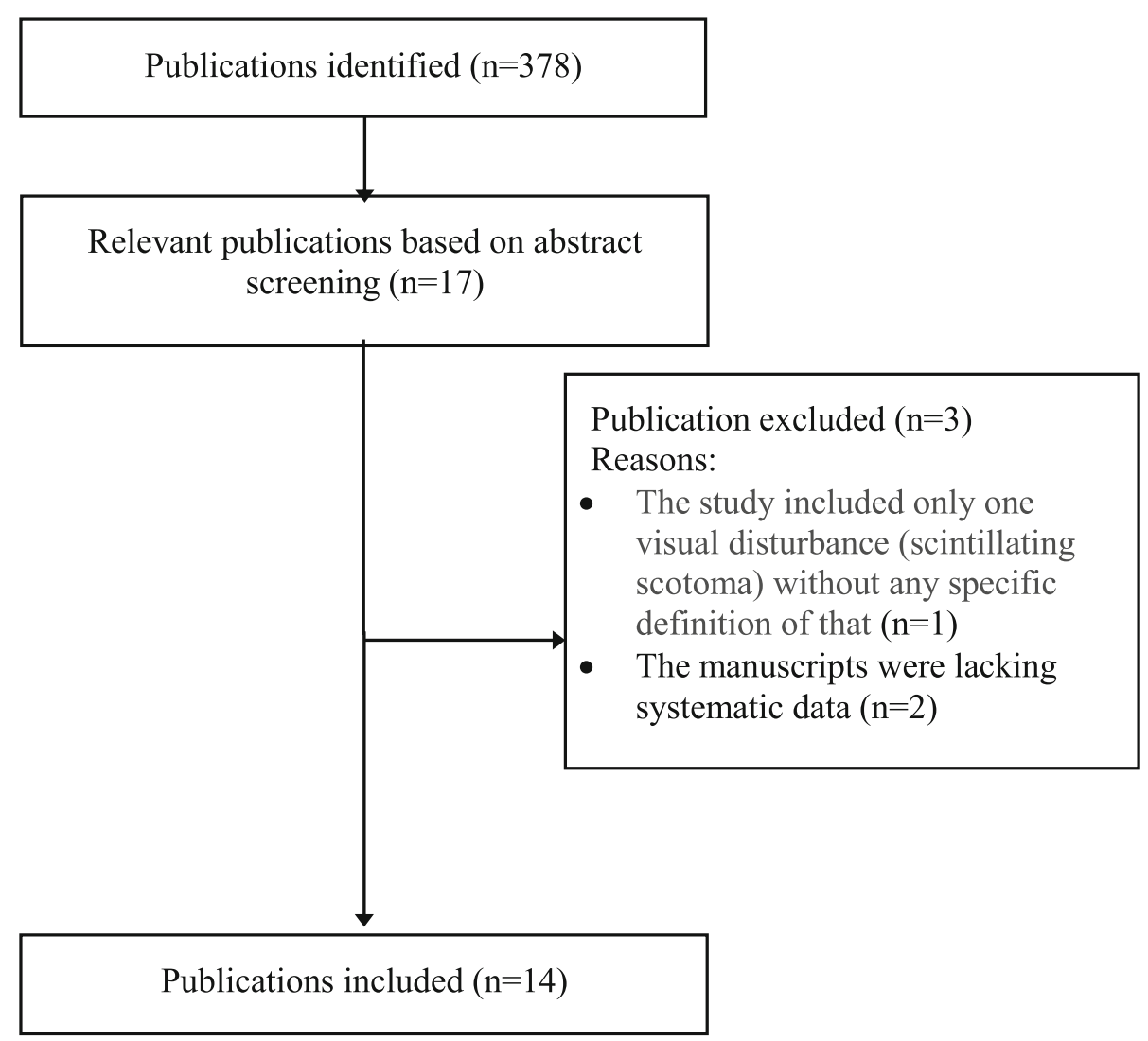

Fig. 1 Flowchart of the review process

the disturbances were separated into more than 10 entities.

Second, in some papers, some of the EVSs are merged into one unique entity (e.g. "scintillating scotoma"), although these represent combinations of features that can be individually experienced during an aura (e.g. "scotoma" and "zigzag or jagged lines"/ "flickering lights") [2].

Third, in some cases the description of a particular VAS is not in line with the rest of literature (e.g. in one study "scintillating scotoma" is described as "a propagating "crescent" of the homonymous type" [17] without any negative visual symptom).

Fourth, some descriptions of EVSs are not sufficiently unequivocal and specific. For example, what is the exact difference between "blind spots" and "black dots"? Does this depend on the size of the area(s) of the visual field involved, or the quality of the EVS (i.e. a blind area versus a black area)?

Fifth, some descriptions are related mostly to a feature of EVSs more than a given EVS. Indeed, this is the case of "flickering lights" which can be related to other EVSs reported in Table 2 (e.g. flashes of bright light, small bright dots). Moreover, we know from our clinical experience that other positive EVS can be flickering (high-frequency micro-movements), such as zigzag lines and round forms. Therefore, we believe that the flickering quality as well as the scintillating quality (high-frequency changes of intensity of light) should be assessed for every EVS (or at least the positive ones) in a prospective study.

In general, the heterogeneity and the limitations in the methodology of the low number of studies that have investigated the features of visual aura, is problematic both for research and clinical practise.

\section{Visual aura symptoms in a clinical context}

MA is a risk factor for several serious cardiovascular conditions, including ischemic and haemorrhagic stroke $[6,7]$, myocardial infarction [7], atrial fibrillation [8] and perioperative stroke [30]. Moreover, the risk of vascular incidents increases up to 13 fold with the use of combined oral contraceptives [31], which is important considering that the majority of migraine patients are women of reproductive age [32, 33]. Furthermore, the differential diagnosis includes cerebrovascular disorders, epilepsy, and other life-threatening neurological conditions. In clinical practice, MA can be very difficult to distinguish from transient ischemic attacks and stroke. Migraine is the third most common stroke mimic, following seizures and psychiatric disorders, and accounts for $18 \%$ of all improper thrombolytic treatment [10]. 


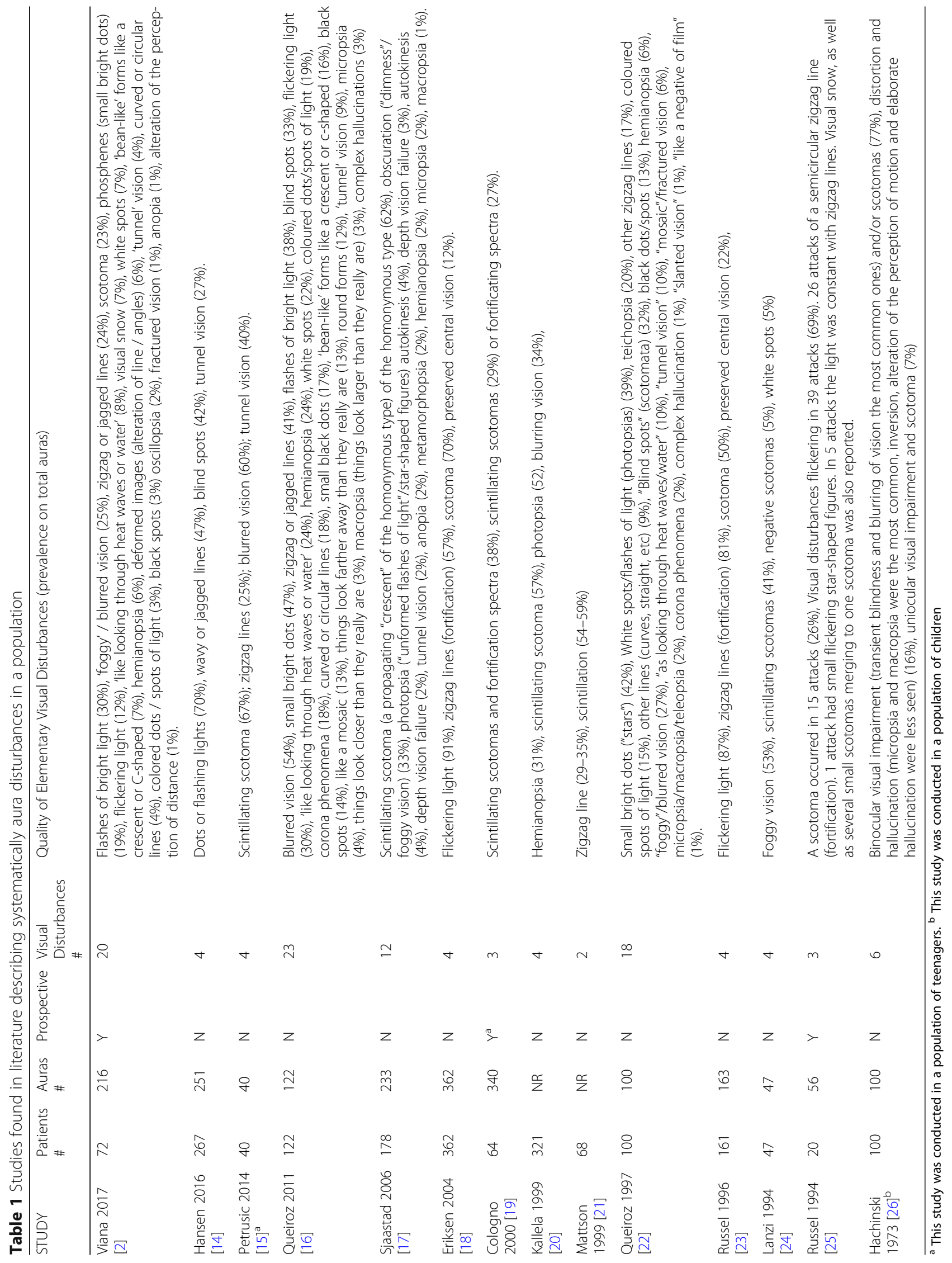


Table 2 List of Elementary Visual Symtpoms (EVSs) of migraine aura as reported in literature and the range of their frequency in the studies

\begin{tabular}{|c|c|}
\hline $\begin{array}{l}\text { Elementary Visual Symptoms } \\
\text { of aura }\end{array}$ & $\begin{array}{l}\text { Frequency } \\
\text { (range \%) }\end{array}$ \\
\hline $\begin{array}{l}\text { 1. Flashes of bright light / unformed flashes of light / } \\
\text { star-shaped figures }\end{array}$ & $16-38$ \\
\hline 2. "Foggy'/blurred vision or "dimness" & $25-54$ \\
\hline 3. Zigzag or jagged lines & $24-81$ \\
\hline 4. Scotoma & $23-77$ \\
\hline 5. Blind spots (scotomata) & 32 \\
\hline 6. Black dots & $3-17$ \\
\hline 7. Phosphenes (small bright dots) & $19-70$ \\
\hline 8. Flickering light & $12-91$ \\
\hline 9. 'Like looking through heat waves or water' & $8-24$ \\
\hline 10. Visual snow & 7 \\
\hline 11. White Spots & $7-22$ \\
\hline 12. 'Bean-like' forms like a crescent or C-shaped & 7 \\
\hline 13. Hemianopsia & $6-24$ \\
\hline $\begin{array}{l}\text { 14. Deformed images (alteration of line/ angles) / } \\
\text { Metamorphopsia }\end{array}$ & $2-6$ \\
\hline 15. 'Tunnel' vision & $4-27$ \\
\hline 16. Curved or circular lines & $4-18$ \\
\hline 17. Round forms & 12 \\
\hline 18. Colored dots / spots of light & $3-19$ \\
\hline $\begin{array}{l}\text { 19. Oscillopsia /autokinesis (movement of } \\
\text { stationary objects) }\end{array}$ & $2-4$ \\
\hline 20. Like a mosaic & 13 \\
\hline 21. Fractured Vision & 1 \\
\hline 22. Corona phenomena & $2-18$ \\
\hline 23. Anopia & $1-2$ \\
\hline 24. Things look farther away than they really are & $1-13$ \\
\hline 25. Things look closer than they really are & $1-3$ \\
\hline 26. Macropsia (things look larger than they really are) & $1-3$ \\
\hline 27. Micropsia (things look smaller than they really are) & $2-4$ \\
\hline 28. "Like a negative of film" & 1 \\
\hline 29. "Slanted vision" & 1 \\
\hline 30. Complex hallucinations & $1-3$ \\
\hline
\end{tabular}

Vice versa, patients with overlooked strokes in an emergency department setting most often receive an initial misdiagnosis of "migraine" [34].

Therefore, it is of utmost importance to correctly diagnose patients with MA in order to effectively distinguish MA from other, potentially life-threatening, conditions. Indeed, the quality of VASs is one of the most important features and we believe that establishing a consensus in the form of an official list of all MA visual symptoms is essential.

\section{Future perspectives}

After reviewing all data, we have made a list of the 30 EVSs described in clinical studies so far. After that, we created a new list that can be used in future clinical studies (Table 3). We decreased the number of EVSs from 30 to 25 as: i) we put together eight items as we felt they were difficult to distinguish (namely "blind spots" and "black dots", "micropsia" and "things look closer than they really are", macropsia and "things look farther away than they really are", "slanted vision" and

Table 3 Proposed list of all EVS of migraine aura and their description

\begin{tabular}{|c|c|}
\hline Proposed Name & Description \\
\hline 1. Bright light ${ }^{c}$ & Single area of bright light \\
\hline 2. Foggy/blurred vision & Foggy or blurred vision \\
\hline 3. Zigzag lines ${ }^{\mathrm{ac}}$ & Zigzag or jagged lines \\
\hline 4. Scotoma & Single blind area \\
\hline 5. Scotomata & Several blind/black areas \\
\hline 6. Small bright dots ${ }^{c}$ & Small bright dots/stars \\
\hline 7. White dots/round forms $s^{\text {abc }}$ & Medium sized white dots/round forms \\
\hline 8. Colored dots/round forms ${ }^{\text {abc }}$ & Medium sized coloured dots/round forms \\
\hline 9. Lines (colored lines) & Lines (colored lines) \\
\hline 10. Geometrical shapes ${ }^{\mathrm{abc}}$ & Geometrical shapes \\
\hline $\begin{array}{l}\text { 11. 'Like looking through heat } \\
\text { waves, water or oil' }\end{array}$ & $\begin{array}{l}\text { 'Like looking through heat waves, } \\
\text { water or oil' }\end{array}$ \\
\hline 12. Visual snow & $\begin{array}{l}\text { Dynamic, continuous, tiny dots usually } \\
\text { black/gray on white background and } \\
\text { gray/white on black background }\end{array}$ \\
\hline 13. 'Bean-like' forms ${ }^{\mathrm{abc}}$ & $\begin{array}{l}\text { 'Bean-like' forms like a crescent or } \\
\text { C-shaped }\end{array}$ \\
\hline 14. Hemianopsia & Blindness of half of the visual field \\
\hline 15. Deformed images & $\begin{array}{l}\text { Deformed images (alteration of } \\
\text { lines/angles) }\end{array}$ \\
\hline 16. Tunnel vision & Blindness in the whole periphery \\
\hline 17. Oscillopsia & Movement of stationary objects \\
\hline 18. Mosaic vision & Seeing mosaic-like \\
\hline 19. Fractured objects & Seeing fractured objects \\
\hline 20. Corona effect ${ }^{\mathrm{abc}}$ & An extra edge on objects \\
\hline 21. Anopia & Total blindness \\
\hline 22. Micropsia & $\begin{array}{l}\text { Objects appear smaller or more distant } \\
\text { than they actually are }\end{array}$ \\
\hline 23. Macropsia & $\begin{array}{l}\text { Objects appear larger or closer than they } \\
\text { actually are }\end{array}$ \\
\hline 24. Like a negative film & Seeing like a negative film \\
\hline 25. Complex hallucinations ${ }^{\mathrm{ac}}$ & $\begin{array}{l}\text { Visual perception of something } \\
\text { not present (e.g. objects, animals, } \\
\text { and persons) }\end{array}$ \\
\hline
\end{tabular}

For some EVSs, when reported, patients should be asked about some additional features: ${ }^{\mathrm{a}}$ colour; ${ }^{\mathrm{b}}$ internal pattern (suggested text: "If the inside of the EVS does not have a homogeneous color but is made up an internal pattern (for example zigzag lines or chessboard) please describe it in words"); ${ }^{c}$ scintillation / flickering (suggested text: "Is/are EVS scintillating (like stars or intermittent lights) and/or flickering (as rapid movements like the wings of a butterfly)?") 
"deformed images") and we deleted "flickering lights", as "flickering" (as well as "scintillation") is a feature that can be used to describe other positive EVSs reported in Table 2. Therefore, we propose that some EVSs should be further characterized by determining the presence of "scintillation" and/or "flickering" (Table 2). In addition, we propose that some EVS should be further characterized by their colour and "internal pattern" (Table 2).

The next step will be to apply this list to clinical studies (1) in patients with MA to better assess the frequency of the different EVSs, thereby establishing which EVSs are the most prevalent and which are clinically meaningful to include in a consensus list; (2) in patients with other visual disturbances (either due to CNS or ocular disorders) to assess the specificity and sensibility of each EVS with respect to MA. This improved description of VASs is important to increase the understanding of other aspects of MA. Pathophysiological studies, e.g. involving neuroimaging and neurophysiology, would benefit from an improved endophenotyping of patients. As an example, a recent functional MRI study suggested that different types of migraine VASs (negative vs. positive) correspond to different types of cerebral dysfunction [35]. Different VAS phenotypes may therefore prove to differ in terms of prognosis, risk of cardiovascular disease, and response to treatment.

\section{Conclusion}

We created a comprehensive list of VASs reported by migraine patients based on all currently available data from clinical studies. The most frequently reported symptoms were flashes of bright light, "foggy" vision, zigzag lines, and scotoma. We observed a lack of prospective studies and a relatively high degree of discrepancy between studies, likely mostly due to differences in the terminology used to describe VASs. We emphasize the importance of an improved classification of migraine VASs and propose that an official list of visual symptoms should be developed for this purpose, preferably within the context of the International Classification of Headache Disorders of the International Headache Society.

\section{Abbreviations}

EVS: Elementary visual symptom; ICHD: International Classification of Headache Disorders; MA: Migraine aura; VAS: Visual aura symptom

\section{Acknowledgements}

Not applicable.

\section{Funding}

The article-processing charges for the article has been sponsored by the European Headache Federation.

\section{Availability of data and materials}

The datasets used and/or analysed during the current study are available from the corresponding author on reasonable request.

\section{Authors' contributions}

MV designed the review. MV and $\mathrm{AH}$ were involved in the review of all the abstracts found with the search strategy. ET was involved in the abstract review process in case of disagreement. MV extracted relevant data from included articles creating the three tables and drafted the manuscript. AH, EAT, TPD and CZ critically reviewed the manuscript. All authors read and approved the final manuscript.

\section{Authors' information}

Not applicable.

Ethics approval and consent to participate

Not applicable.

Consent for publication

Not applicable.

\section{Competing interests}

The authors declare that they have no competing interests.

\section{Publisher's Note}

Springer Nature remains neutral with regard to jurisdictional claims in published maps and institutional affiliations.

\section{Author details}

${ }^{1}$ Headache Center, Neurocenter of Southern Switzerland (NSI), Regional Hospital Lugano, Via Tesserete 46, 6901 Lugano, Switzerland. ${ }^{2}$ Headache Group, Department of Basic and Clinical Neurosciences, King's College London, London, UK. ${ }^{3}$ Department of Neuromedicine and Movement Science, Norwegian University of Science and Technology, Trondheim, Norway. ${ }^{4}$ Norwegian Advisory Unit on Headache, St. Olavs University Hospital, Trondheim, Norway. ${ }^{5}$ Danish Headache Center, Department of Neurology, Rigshospitalet Glostrup, Glostrup, Denmark. ${ }^{6}$ Faculty of biomedical Sciences, Università della Svizzera Italiana, Via Buffi 13, 6900 Lugano, Switzerland.

Received: 6 February 2019 Accepted: 26 April 2019

Published online: 30 May 2019

\section{References}

1. Russell MB, Rasmussen BK, Thorvaldsen P, Olesen J (1995) Prevalence and sex-ratio of the subtypes of migraine. Int J Epidemiol 24(3):612-618

2. Viana M, Sances G, Linde M, Ghiotto N, Guaschino E, Allena M et al (2017) Clinical features of migraine aura: results from a prospective diary-aided study. Cephalalgia 37(10):979-989

3. Charles A (2013) Migraine: a brain state. Curr Opin Neurol 26(3):235-239

4. Lauritzen M, Dreier JP, Fabricius M, Hartings JA, Graf R, Strong AJ (2011) Clinical relevance of cortical spreading depression in neurological disorders: migraine, malignant stroke, subarachnoid and intracranial hemorrhage, and traumatic brain injury. J Cereb Blood Flow Metab 31(1):17-35

5. Lauritzen M (1994) Pathophysiology of the migraine aura. The spreading depression theory. Brain 117 ( Pt 1:199-210

6. Spector JT, Kahn SR, Jones MR, Jayakumar M, Dalal D, Nazarian S (2010) Migraine headache and ischemic stroke risk: an updated meta-analysis. Am J Med 123(7):612-624

7. Mahmoud AN, Mentias A, Elgendy AY, Qazi A, Barakat AF, Saad M et al (2018) Migraine and the risk of cardiovascular and cerebrovascular events: a meta-analysis of 16 cohort studies including 1152407 subjects. BMJ Open 8(3):e020498

8. Sen S, Androulakis XM, Duda V, Alonso A, Chen LY, Soliman EZ et al (2018) Migraine with visual aura is a risk factor for incident atrial fibrillation: a cohort study. Neurology 91(24):e2202-e2e10

9. Schwedt TJ, Demaerschalk BM, Dodick DW (2008) Patent foramen ovale and migraine: a quantitative systematic review. Cephalalgia 28(5):531-540

10. Terrin A, Toldo G, Ermani M, Mainardi F, Maggioni F (2018) When migraine mimics stroke: a systematic review. Cephalalgia 38(14):2068-2078

11. Martinez JV, Specialli JG (1997) Migraine with visual aura versus occipital epilepsy. Headache 37(2):113

12. Queiroz LP, Friedman DI, Rapoport AM, Purdy RA (2012) Response to Panayiotopoulos: Visual aura of migraine versus visual occipital lobe seizures. Cephalalgia 32(8):655 
13. (IHS) HCCotIHS (2018) The international classification of headache disorders, 3rd edition. Cephalalgia 38(1):1-211

14. Hansen JM, Goadsby PJ, Charles AC (2016) Variability of clinical features in attacks of migraine with aura. Cephalalgia 36(3):216-224

15. Petrusic I, Pavlovski V, Vucinic D, Jancic J (2014) Features of migraine aura in teenagers. J Headache Pain 15:87

16. Queiroz LP, Friedman DI, Rapoport AM, Purdy RA (2011) Characteristics of migraine visual aura in southern Brazil and northern USA. Cephalalgia 31(16):1652-1658

17. Sjaastad O, Bakketeig LS, Petersen HC (2006) Migraine with aura: visual disturbances and interrelationship with the pain phase. Vaga study of headache epidemiology. J Headache Pain 7(3):127-135

18. Eriksen MK, Thomsen LL, Andersen I, Nazim F, Olesen J (2004) Clinical characteristics of 362 patients with familial migraine with aura. Cephalalgia 24(7):564-575

19. Cologno D, Torelli P, Cademartiri C, Manzoni GC (2000) A prospective study of migraine with aura attacks in a headache clinic population. Cephalalgia 20(10):925-930

20. Kallela M, Wessman M, Farkkila M, Palotie A, Koskenvuo M, Honkasalo ML et al (1999) Clinical characteristics of migraine in a population-based twin sample: similarities and differences between migraine with and without aura. Cephalalgia 19(3):151-158

21. Mattsson P, Lundberg PO (1999) Characteristics and prevalence of transient visual disturbances indicative of migraine visual aura. Cephalalgia 19(5):479-484

22. Queiroz LP, Rapoport AM, Weeks RE, Sheftell FD, Siegel SE, Baskin SM (1997) Characteristics of migraine visual aura. Headache 37(3):137-141

23. Russell MB, Olesen J (1996) A nosographic analysis of the migraine aura in a general population. Brain 119(Pt 2):355-361

24. Lanzi G, Balottin U, Borgatti R (1994) A prospective study of juvenile migraine with aura. Headache 34(5):275-278

25. Russell MB, Iversen HK, Olesen J (1994) Improved description of the migraine aura by a diagnostic aura diary. Cephalalgia 14(2):107-117

26. Hachinski VC, Porchawka J, Steele JC (1973) Visual symptoms in the migraine syndrome. Neurology 23(6):570-579

27. Manzoni GC, Farina S, Lanfranchi M, Solari A (1985) Classic migraine--clinical findings in 164 patients. Eur Neurol 24(3):163-169

28. Alvarez WC (1960) The migrainous scotoma as studied in 618 persons. Am J Ophthalmol 49:489-504

29. Panayiotopoulos CP (1994) Elementary visual hallucinations in migraine and epilepsy. J Neurol Neurosurg Psychiatry 57(11):1371-1374

30. Timm FP, Houle TT, Grabitz SD, Lihn AL, Stokholm JB, Eikermann-Haerter K et al (2017) Migraine and risk of perioperative ischemic stroke and hospital readmission: hospital based registry study. BMJ 356:6635

31. Tzourio C, Tehindrazanarivelo A, Iglesias S, Alperovitch A, Chedru F, d'Anglejan-Chatillon J et al (1995) Case-control study of migraine and risk of ischaemic stroke in young women. BMJ 310(6983):830-833

32. Lipton RB, Bigal ME, Diamond M, Freitag F, Reed ML, Stewart WF et al (2007) Migraine prevalence, disease burden, and the need for preventive therapy. Neurology 68(5):343-349

33. Stovner L, Hagen K, Jensen R, Katsarava Z, Lipton R, Scher A et al (2007) The global burden of headache: a documentation of headache prevalence and disability worldwide. Cephalalgia 27(3):193-210

34. Tarnutzer AA, Lee SH, Robinson KA, Wang Z, Edlow JA, Newman-Toker DE (2017) ED misdiagnosis of cerebrovascular events in the era of modern neuroimaging: a meta-analysis. Neurology 88(15):1468-1477

35. Arngrim N, Hougaard A, Ahmadi K, Vestergaard MB, Schytz HW, Amin FM et al (2017) Heterogenous migraine aura symptoms correlate with visual cortex functional magnetic resonance imaging responses. Ann Neurol 82(6): 925-939

\section{Ready to submit your research? Choose BMC and benefit from:}

- fast, convenient online submission

- thorough peer review by experienced researchers in your field

- rapid publication on acceptance

- support for research data, including large and complex data types

- gold Open Access which fosters wider collaboration and increased citations

- maximum visibility for your research: over $100 \mathrm{M}$ website views per year

At $\mathrm{BMC}$, research is always in progress.

Learn more biomedcentral.com/submissions 